\title{
SCIENTIFIC REPORTS

\section{Association of dietary patterns and endoscopic gastric mucosal atrophy in an adult Chinese population}

\author{
Song Lin ${ }^{1}$, Tao Gao ${ }^{2}$, Chongxiu Sun ${ }^{1}$, Mengru Jia ${ }^{1}$, Chengxia Liu ${ }^{2}$, Xingbin Ma ${ }^{2}$ \& Aiguo $\mathrm{Ma}^{1 *}$
}

Atrophy gastritis harbor a high risk for the development of dysplasia and gastric cancer. The study investigated the relationships of specific dietary patterns and endoscopic gastric mucosal atrophy. In this cross-sectional study, we enrolled 574 consecutive outpatients who were diagnosed as chronic gastritis according to endoscopic examination. Dietary intakes of study individuals was assessed using the semi-quantitative food group frequency questionnaire. Logistic regression analyses were used to evaluate the relationship between dietary patterns and endoscopic gastric mucosal atrophy adjusted for potential confounders. A total of 574 participants were included, 286 with endoscopic gastric mucosal atrophy. Three dietary patterns were identified by factor analysis. "Alcohol and fish" (tertile 1 vs. tertile 3 : adjusted odds ratio $=1.85,95 \%$ confidence interval: $1.06-3.22$ ) and "coarse cereals" (tertile 1 vs. tertile 3 : adjusted odds ratio $=2.05,95 \%$ confidence interval: $1.24-3.39$ ) were associated with an increased risk for endoscopic gastric mucosal atrophy but a "traditional" pattern was not. Dietary pattern was not associated with gastric mucosal atrophy in women or in participants with $H$. pylori infection. A high adherence to both "Alcohol and Fish" and "Coarse cereals" dietary patterns seem to be associated with higher odds of endoscopic gastric mucosal atrophy in men and in patients without H. pylori infection. Further prospective cohort studies needed to confirm these findings.

Gastric mucosal atrophy is a common, age-related multifactorial disease associated with Helicobacter pylori infection and $\operatorname{diet}^{1-3}$. It is estimated that as many as $25 \%$ of people worldwide are at risk of loss or atrophy of normal gastric mucosal glands ${ }^{4}$. The prevalence of chronic atrophy gastritis varies regionally, from $25.8 \%$ in China ${ }^{5}$ to $40.7 \%$ in Korea ${ }^{6}$. Gastric mucosal atrophy is a precursor lesion in the development of gastric carcinoma ${ }^{7,8}$. The overall incidence of gastric cancer has been declining in Asian countries including China ${ }^{9}$, but most people infected by $H$. pylori remain asymptomatic for life despite evidence of chronic gastritis ${ }^{10}$. H. pylori infection alone might not be sufficient to cause gastric cancer even though the World Health Organization considers it to be a class-I carcinogen. Diet may also play a key role in gastric carcinogenesis. For example, some studies have found that a high-salt diet was independently associated with gastric carcinoma and that Western diets rich in salt, meat, animal fat, starchy food and alcohol increase the risk of precancerous lesions or gastric cancer ${ }^{11-17}$. Diets rich in fruits and vegetables appear to reduce gastric cancer risk ${ }^{18,19}$. Completion of the sequence of events that occur in the gastric mucosa before the manifestation of gastric cancer may take decades ${ }^{8}$. Most studies of the role of diet have focused on gastric cancer, but increased awareness of the association of dietary factors with development of precancerous lesions would help in the formulation of targeted prevention.

Rather than focusing on individual nutrients or foods, dietary pattern analysis might be the most feasible method to assess the relationship between diet and disease and to help nutritionists to provide dietary recommendations in public health practice ${ }^{20}$. The characterization of diet patterns by factor analysis has been proven to predict the risk of coronary heart disease ${ }^{21}$, colorectal cancer ${ }^{22}$, and gallbladder disease ${ }^{23}$. To our knowledge, the relationship of dietary factors and endoscopic gastric mucosal atrophy has not been well established. The study aim was to identify the role of dietary patterns and risk factors associated with gastritis and of potential help in the prevention of gastric carcinoma.

\footnotetext{
${ }^{1}$ The College of Public Health, Qingdao University, 38 Dengzhou Road, Qingdao, Shandong, 266021, China. ${ }^{2}$ Digestive endoscopy center, Hospital Affiliated Binzhou Medical University, Binzhou, 256603, China. *email: magfood@qdu.edu.cn
} 


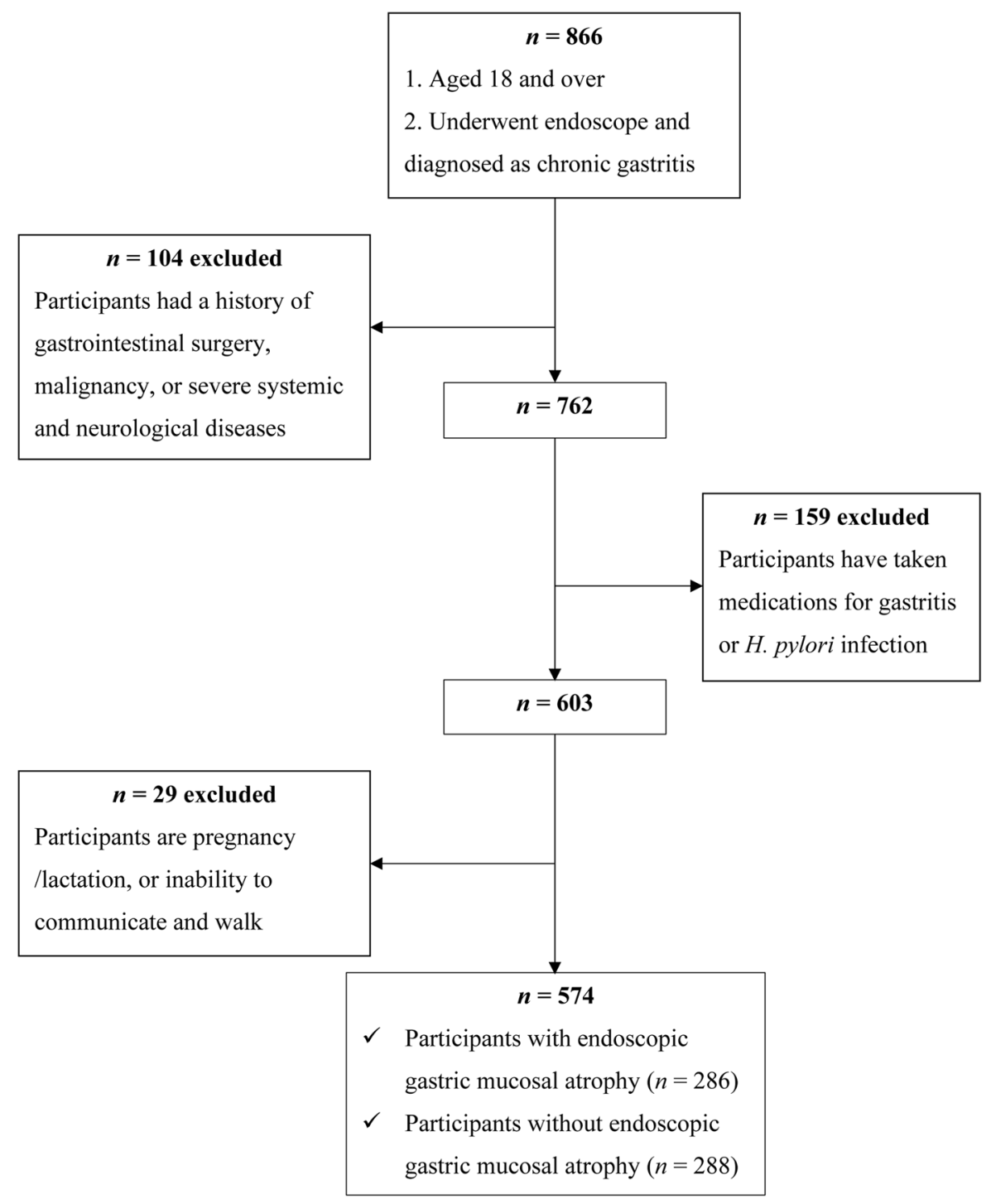

Figure 1. Flow chart of the screening process of the selection of eligible participants.

\section{Methods}

Study population. This cross-sectional study investigated the relationship of diet and endoscopic gastric mucosal atrophy in a Han Chinese population in Binzhou city Shandong Province, China. The participants were recruited between April and October 2018 at the Outpatient Digestive Endoscopy Center at the Binzhou Medical University Affiliated Hospital, which is the only tertiary hospital in the region. Patients $\geq 18$ years of age with a endoscopic diagnosis of chronic gastritis were eligible for inclusion. Patients with a history of gastrointestinal surgery, malignancy, or severe systemic of neurological disease, a history of gastritis or $H$. pylori infection, pregnancy or at lactation, or unable to communicate or walk normally were excluded. A total of 574 consecutive outpatients who met the above eligibility were included in the analyses (Fig. 1). The study was approved by the ethics committee of Binzhou Medical University Hospital and conducted in line with the ethical guidelines of Declaration of Helsinki. Informed consent was obtained from all participants.

Assessment of dietary intake. Dietary intake during the previous year was assessed with a semiquantitative food group frequency questionnaire (FGFQ) administered by medical staff and study investigators during face-to-face interviews. The questionnaire included items on the frequency ("three times a day", "twice a day", "once a day", "two to three times a week", "once a week", "once every two weeks", "once a month", or "never") and portion size in grams of 23 food group items. The daily intake in grams was calculated by multiplying the portion size of each food group item by the daily consumption frequency $(3,2,1,0.357,0.143,0.071,0.033$, or 0$)$. The patients were asked to recall consumption of food groups rather than nutrients during the previous year because of the short 20-minute interval between administration of the spray oral anesthetic and the endoscopy procedure. Commonly consumed food groups and recipes were chosen by a nutritionist (Supplementary Table 1). Only 180 individuals completed both FGFQ and a 24-h dietary recall. The Spearman rank correlations are shown in 
Supplementary Table 2. Total energy intake (kcal/day) was calculated by NutriSurvey (http://www.nutrisurvey.de) using the $24 \mathrm{~h}$ recall data.

Diagnosis of chronic atrophic gastritis and H. pylori infection. Endoscopies were performed and evaluated by experienced practitioners. Gastric mucosal atrophy was described and graded by the Chinese Society of Digestive Endoscopy criteria ${ }^{24}$. A rapid urease test was used to diagnose H. pylori infection ${ }^{25}$.

Participant characteristics. Potential confounding social and demographic variables, including age, sex, height, weight, body mass index (BMI, $\left.\mathrm{kg} / \mathrm{m}^{2}\right)$, education, place of residence, occupation, income, smoking status, drinking status, and histories of diabetes, hypertension, and anticoagulant use were collected with a structured questionnaire.

Statistical analysis. Statistical analysis was performed with SPSS 25.0 (IBM Corp., Armonk, NY, USA) and Stata version 15.1 (Stata Corporation, College Station, TX, USA). All $p$-values were two-sided. Dietary patterns were analyzed by principle component analysis (PCA) with varimax rotation. The number of patterns was determined by the cumulative contribution rate of variance, eigenvalue $>1.45$, and the interpretability of the results. Food groups with a rotated factor loading of $>|0.4|$ were considered the primary components of each pattern. Dietary pattern scores were calculated by summing the products of the standardized intakes of each food group multiplied by regression coefficients and were reported as tertiles. The values of continuous variables were reported as means and standard deviations. Categorical variables were reported as numbers and percentages. Between-group differences in participants with or without endoscopic gastric mucosal atrophy were compared by Student's $t$-tests. Chi-square tests were used to compare percentage differences of categorical variables in participants with or without endoscopic gastric mucosal atrophy. Differences in patient characteristics across dietary pattern scores were evaluated by chi-square tests for categorical variables and the analysis of variance for continuous variables. The association of adherence to each dietary pattern and the odds of endoscopic gastric mucosal atrophy was tested by binary logistic regression. Model 1 was adjusted for age and sex. Model 2 included BMI, education $(<6,6-12$, or $>12$ years), residence (urban or rural), marital status (single, divorced, widowed, or married), occupation (supervisory, company employee, laborer, self-employed, student, farmer, or retried) income ( $<1000,1000-3000,>3000 \mathrm{CNY} /$ month/individual), smoking (yes or no), drinking (yes or no). Model 3 was further adjusted for $H$. pylori infection (yes or no), history of diabetes (yes or no), history of hypertension (yes or no), history of anticoagulant use (yes or no), and total energy intake. Assuming that total energy intake was missing in randomly distributed participants, missing data were compensated by multivariate imputation of chained equations ${ }^{26,27}$. Twenty imputed datasets were created to reduce sampling variability and the estimates were combined based on Rubin's rules ${ }^{28}$.

\section{Results}

The characteristics of the 574 participants are shown in Table 1. The point prevalence of endoscopic gastric mucosal atrophy was $49.8 \%$. Participants with or without endoscopic gastric mucosal atrophy showed significant differences in terms of marital status $(p=0.044)$, occupation $(p=0.001), H$. pylori infection status $(p<0.001)$, history of hypertension $(p=0.001)$, history of taking anticoagulants $(p=0.015)$. Compared with those without endoscopic gastric mucosal atrophy, participants with gastric mucosal atrophy showed older age $(p<0.001)$, lower education $(p<0.001)$, and higher income $(p=0.012)$.

Extraction of dietary patterns. The PCA analysis yielded three independent diet patterns that explained $24.5 \%$ of the variation in food consumption (Table 2). The first was "alcohol and fish," which included high consumption of wine, beer, fresh water and sea fish. The second was "traditional," with high consumption of vegetables, wheat products and red meat, and the third was "coarse cereals," with high consumption of whole grain cereals, legumes, and poultry. The participant characteristics and dietary pattern tertiles are shown in Table 3. Participants with an "alcohol and fish" pattern were more likely to be men, smokers, drinkers, supervisory or company employees, urban residents with high incomes and education levels, and histories of hypertension or anticoagulant use. Those adhering to a "traditional" pattern were more likely to be men, younger, smokers, drinkers, have high incomes, low BMI, and low education level. Those adhering to the "coarse cereals" pattern were more likely to be men, younger, supervisory employees, and urban residents with high education and income levels.

After controlling for potential confounders, participants who adhered to the "alcohol and fish" pattern were more likely to be drinkers, non-farmers, without a history of hypertension. Those who adhered to the "traditional" pattern were more likely to be men, younger than 50 years of age, and drinkers. Those who adhered to the "coarse cereals" pattern were more likely to be smokers, have an H. pylori infection, and have a high education level (Supplementary Table 3).

Association between dietary patterns and endoscopic gastric mucosal atrophy. Table 4 shows the effect of adherence to the dietary patterns on the risk of endoscopic gastric mucosal atrophy. Model 1 found that the "alcohol and fish" and "coarse cereals" patterns were both positively associated with endoscopic gastric mucosal atrophy but that the "traditional" pattern was not. After controlling for potential confounders, adherence to the "alcohol and fish" dietary pattern was related to an increased prevalence of endoscopic gastric mucosal atrophy, but the association was significant only for the highest tertile (tertile 1 vs. tertile 3 adjusted OR $=1.84$, 95\% CI: $1.06-3.20$, $p$-value for trend =0.040). Adherence to the "coarse cereals" pattern also increased the risk of endoscopic gastric mucosal atrophy (tertile 1 vs. tertile 3: adjusted OR $=2.04,95 \%$ CI: $1.24-3.38$, $p$-value for trend $=0.005$ ). Adherence to the "traditional" pattern was not found to influence the risk of endoscopic gastric mucosal atrophy. 


\begin{tabular}{|c|c|c|c|}
\hline Variables $^{\mathrm{a}}$ & $\begin{array}{l}\text { Participants with endoscopic } \\
\text { gastric mucosal atrophy } \\
\mathrm{n}=286(49.8 \%)\end{array}$ & $\begin{array}{l}\text { Participants without } \\
\text { endoscopic gastric mucosal } \\
\text { atrophy } n=288(50.2 \%)\end{array}$ & $P^{\mathrm{b}}$ \\
\hline Gender & & & 0.551 \\
\hline Male & $162(56.6 \%)$ & $156(54.2 \%)$ & \\
\hline Female & $124(43.4 \%)$ & $132(45.8 \%)$ & \\
\hline Age group, year & & & $<0.001$ \\
\hline $18-44$ & $52(18.2 \%)$ & $154(53.5 \%)$ & \\
\hline $45-54$ & $109(38.1 \%)$ & $88(30.6 \%)$ & \\
\hline$\geq 55$ & $125(43.7 \%)$ & $46(16.0 \%)$ & \\
\hline $\mathrm{BMI}, \mathrm{kg} / \mathrm{m}^{\mathrm{b}}$ & $24.1 \pm 3.46$ & $23.4 \pm 3.64$ & 0.020 \\
\hline Residence & & & 0.606 \\
\hline Urban & $84(29.4 \%)$ & $79(27.4 \%)$ & \\
\hline Rural & $202(70.6 \%)$ & $209(72.6 \%)$ & \\
\hline Year of education, year & & & $<0.001$ \\
\hline$<6$ & $80(28.0 \%)$ & $54(18.8 \%)$ & \\
\hline $6-12$ & $171(59.8 \%)$ & $165(57.3 \%)$ & \\
\hline$>12$ & $35(12.2 \%)$ & $69(24.0 \%)$ & \\
\hline \multicolumn{4}{|l|}{ Marital status } \\
\hline Single/Divorced/Widowed & $4(1.4 \%)$ & $12(4.2 \%)$ & 0.044 \\
\hline Married & $282(99.6 \%)$ & $276(95.8 \%)$ & \\
\hline Occupation & & & 0.001 \\
\hline Authority unit & $39(13.6 \%)$ & $52(18.1 \%)$ & \\
\hline Company employee & $12(4.2 \%)$ & $18(6.3 \%)$ & \\
\hline Worker & $39(13.6 \%)$ & $46(16.0 \%)$ & \\
\hline Self-employer & $41(14.3 \%)$ & $61(21.2 \%)$ & \\
\hline Student & $2(0.7 \%)$ & $10(3.5 \%)$ & \\
\hline Farmer & $141(49.3 \%)$ & $93(32.3 \%)$ & \\
\hline Retried & $12(4.2 \%)$ & $8(2.8 \%)$ & \\
\hline Income, $\mathrm{CNY} /$ month/per-individual & & & 0.007 \\
\hline$<1000$ & $67(23.4 \%)$ & $57(19.8 \%)$ & \\
\hline $1001-3000$ & $110(38.5 \%)$ & $84(29.2 \%)$ & \\
\hline$>3000$ & $109(38.1 \%)$ & $147(51.0 \%)$ & \\
\hline Smoking & & & 0.455 \\
\hline Yes & $133(46.5 \%)$ & $125(43.4 \%)$ & \\
\hline No & $153(53.5 \%)$ & $163(56.6 \%)$ & \\
\hline Drinking & & & 0.474 \\
\hline Yes & $78(27.3 \%)$ & $71(24.7 \%)$ & \\
\hline No & $208(72.7 \%)$ & $217(75.3 \%)$ & \\
\hline H. pylori infection & & & $<0.001$ \\
\hline Yes & $109(38.4 \%)$ & $55(19.2 \%)$ & \\
\hline No & $175(61.6 \%)$ & $231(80.8 \%)$ & \\
\hline \multicolumn{4}{|l|}{ History of diabetes } \\
\hline Yes & $19(6.6 \%)$ & $13(4.5 \%)$ & 0.266 \\
\hline No & $267(93.4 \%)$ & $275(95.5 \%)$ & \\
\hline History of hypertension & & & 0.001 \\
\hline Yes & $49(17.1 \%)$ & $22(7.6 \%)$ & \\
\hline No & $237(82.9 \%)$ & $266(92.4 \%)$ & \\
\hline History of taking anticoagulants & & & 0.015 \\
\hline Yes & $22(7.7 \%)$ & $9(3.1 \%)$ & \\
\hline No & $264(92.3 \%)$ & $279(96.9 \%)$ & \\
\hline Total energy intake, $\mathrm{kcal} / \mathrm{day}^{\mathrm{c}}$ & $1804.3 \pm 719.7$ & $1830.8 \pm 706.1$ & 0.868 \\
\hline
\end{tabular}

Table 1. General characteristics of participants by having or not having endoscopic gastric mucosal atrophy.

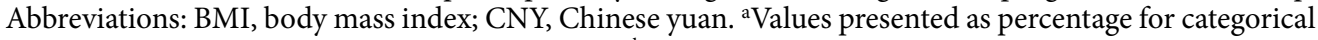
variables and mean $\pm \mathrm{SD}$ for continuous variables. ${ }^{\mathrm{b}} \mathrm{Chi}$-square test was used to compare the percentage between participants with or without endoscopic gastric mucosal atrophy. Student's t-test analyses was used to compare the mean values between participants with or without endoscopic gastric mucosal atrophy. ${ }^{\text {CFrom }}$ 180 individuals (89 participants with endoscopic gastric mucosal atrophy, 91 participants without endoscopic gastric mucosal atrophy). 


\begin{tabular}{|c|c|c|c|}
\hline Food groups & Alcohol and fish & Traditional & Coarse cereals \\
\hline Fresh water fish & 0.74 & - & - \\
\hline Sea fish & 0.73 & - & - \\
\hline Wine & 0.68 & - & - \\
\hline Beer & 0.65 & - & - \\
\hline Legumes & - & - & 0.41 \\
\hline Tea & - & - & - \\
\hline Poultry & - & - & 0.46 \\
\hline Red meat & - & 0.50 & - \\
\hline Sugar-sweetened beverage & - & - & - \\
\hline Potatoes & - & - & - \\
\hline Vegetables & - & 0.73 & - \\
\hline Fruits & - & - & - \\
\hline Lard oil & - & - & - \\
\hline Egg & - & - & - \\
\hline Salted vegetables & - & - & - \\
\hline Soya-bean oil & -- & - & - \\
\hline Coarse cereals & - & - & 0.71 \\
\hline Dairy and its product & - & - & - \\
\hline Cooked wheaten food & - & 0.72 & - \\
\hline Processed meat & - & - & - \\
\hline Corn oil & - & - & - \\
\hline Peanut oil & - & - & - \\
\hline Cooked rice food & - & - & - \\
\hline Percent of variance explained (\%) & $10.30 \%$ & $7.27 \%$ & $6.88 \%$ \\
\hline
\end{tabular}

Table 2. Principal component analysis of 23 food groups. Factor loading $>0.4$ are listed.

The association of dietary pattern and endoscopic gastric mucosal atrophy after stratifying the participants by selected variables is shown in Supplementary Table 4. After controlling for potential confounders, The "coarse cereals" pattern was associated with endoscopic gastric mucosal atrophy in men (tertile 1 vs. tertile 3: adjusted $\mathrm{OR}=3.05$, 95\% CI: $1.45-6.38$, $p$-value for trend $=0.003$ ). The "alcohol and fish" pattern was associated with $H$. pylori infection status (adjusted OR $=2.12(95 \%$ CI: $1.08-4.15$, $p$-value for trend $=0.031)$. The "coarse cereals" pattern was associated with endoscopic gastric mucosal atrophy in patients without $H$. pylori infection (adjusted $\mathrm{OR}=2.35$ (95\% CI: $1.28-4.32$, $p$-value for trend $=0.005)$. The results of sensitivity analysis with or without adjusting for total energy intake were similar (data not shown).

\section{Discussion}

After adjusting for potential confounders, participants with a dietary pattern including high alcohol and fish intake had increased odds of endoscopic gastric mucosal atrophy. The "coarse cereals" pattern also increased the risk of endoscopic gastric mucosal atrophy. Vegetable, wheat, and red meat consumption were not associated with the presence of endoscopic gastric mucosal atrophy. Analysis after stratification revealed that the "alcohol and fish" pattern was associated with an increased risk for endoscopic gastric mucosal atrophy in men but not in women, which might reflect the inclusion of only five female drinkers. The "alcohol and fish" and "coarse cereals" patterns were associated with endoscopic gastric mucosal atrophy in patients without $H$. pylori infection. Although the most common cause of gastritis is $H$. pylori infection, $H$. pylori-negative gastritis was common and more likely in past alcohol drinkers than in patients with $H$. pylori infection ${ }^{29}$.

To the best of our knowledge, this is the first study to investigate the relationship of dietary patterns and chronic atrophic gastritis. Most previous studies investigated the association of dietary patterns and gastric cancer. A meta-analysis of 23 studies reported that diets rich in vegetables, fruit, fish, low-fat milk, and whole grains may decrease the risk of stomach cancer. Western-style diets rich in meats, refined grains, sweets, high-fat dairy products, high-fat gravies, and alcohol may increase the risk of stomach cancer ${ }^{30}$. Another recent meta-analysis of cohort studies found an inverse relationship between the adherence the Mediterranean Diet and gastric cancer risk ${ }^{31}$.

The results of previous studies of the association of diet and chronic atrophic gastritis were limited to consumption of single foods or alcohol consumption. You et al. ${ }^{32}$ revealed that alcohol was a risk factor $(\mathrm{OR}=3.2)$, but Gao et al. ${ }^{33}$ found that life-time moderate beer consumption $(\leq 51.38 \mathrm{~g}$ of alcohol/day) was inversely related to chronic atrophic gastritis $(\mathrm{OR}=0.73)$. The majority of endoscopic and histological data do not support a relationship of alcohol consumption with chronic atrophic gastritis ${ }^{34-36}$. These cross-sectional studies did not find an independent association of alcohol drinking and chronic atrophic gastritis, but small sample sizes make it difficult to confirm the presence or absence of a relationship. A recent retrospective cohort study of 10,185 subjects did find that alcohol consumption was an independent risk factor of mucosal atrophy (adjusted $\mathrm{HR}=1.001,95 \% \mathrm{CI}$ : $1.001-1.002)^{37}$. Both acute and chronic alcohol consumption can alter gastric acid secretion and induce acute gastric mucosal injury by mediating the release of inflammatory factors, granulocyte activation, protease secretion, 


\begin{tabular}{|c|c|c|c|c|c|c|c|c|c|c|c|c|}
\hline \multirow[b]{2}{*}{ Variables $^{\mathrm{a}}$} & \multicolumn{3}{|c|}{ Alcohol and fish } & \multirow[b]{2}{*}{$p^{\mathrm{b}}$} & \multicolumn{3}{|c|}{ Traditional } & \multirow[b]{2}{*}{$p^{\mathrm{b}}$} & \multicolumn{3}{|c|}{ Coarse cereals } & \multirow[b]{2}{*}{$p^{\mathrm{b}}$} \\
\hline & \begin{tabular}{|l|} 
T1 (191) \\
\end{tabular} & T2 (190) & T3 (193) & & T1 (191) & T2 (190) & T3 (193) & & \begin{tabular}{|l|} 
T1 (191) \\
\end{tabular} & T2 (190) & T3 (193) & \\
\hline Gender, males & 39.8 & 48.4 & 77.0 & $<0.001$ & 34.7 & 51.0 & 80.2 & $<0.001$ & 57.1 & 46.8 & 62.2 & 0.009 \\
\hline Age group & & & & 0.372 & & & & 0.011 & & & & 0.001 \\
\hline $18-44$ & 30.9 & 35.8 & 40.9 & & 27.4 & 37.5 & 42.7 & & 29.3 & 32.1 & 46.1 & \\
\hline $45-54$ & 37.2 & 34.7 & 31.1 & & 34.7 & 35.4 & 32.8 & & 39.3 & 40.5 & 23.3 & \\
\hline$\geq 55$ & 31.9 & 29.5 & 28.0 & & 37.9 & 27.1 & 24.5 & & 31.4 & 27.4 & 30.6 & \\
\hline BMI & $23.5 \pm 3.7$ & $23.5 \pm 3.5$ & $24.2 \pm 3.5$ & 0.056 & $23.9 \pm 3.7$ & $23.1 \pm 3.3$ & $24.2 \pm 3.6$ & 0.012 & $23.8 \pm 3.5$ & $23.4 \pm 3.5$ & $24.0 \pm 3.7$ & 0.328 \\
\hline Residence & & & & $<0.001$ & & & & 0.596 & & & & 0.033 \\
\hline Urban & 20.9 & 23.7 & 40.4 & & 31.1 & 26.6 & 27.6 & & 24.1 & 25.8 & 35.2 & \\
\hline Rural & 79.1 & 76.3 & 59.6 & & 68.9 & 73.4 & 72.4 & & 75.9 & 74.2 & 64.8 & \\
\hline Year of education & $<0.001$ & & & & 0.03 & & & & $<0.001$ & & & \\
\hline$<6$ & 29.8 & 23.7 & 16.6 & & 30.5 & 22.9 & 16.7 & & 31.4 & 21.6 & 17.1 & \\
\hline $6-12$ & 59.2 & 61.1 & 55.4 & & 51.6 & 59.4 & 64.6 & & 56.5 & 64.7 & 54.4 & \\
\hline$>12$ & 11.0 & 15.3 & 28.0 & & 17.9 & 17.7 & 18.8 & & 12.0 & 13.7 & 28.5 & \\
\hline Marital status & & & & 0.783 & & & & 0.931 & & & & 0.144 \\
\hline $\begin{array}{l}\text { Single/Divorced/ } \\
\text { Widowed }\end{array}$ & 3.1 & 2.1 & 3.1 & & 3.2 & 2.6 & 2.6 & & 1.6 & 2.1 & 4.7 & \\
\hline Married & 96.9 & 97.9 & 96.9 & & 96.8 & 97.4 & 97.4 & & 98.4 & 97.9 & 95.3 & \\
\hline Occupation & & & & $<0.001$ & & & & 0.718 & & & & 0.001 \\
\hline Authority unit & 11.5 & 10.5 & 25.4 & & 15.3 & 14.6 & 17.7 & & 9.4 & 14.2 & 23.8 & \\
\hline Company employee & 1.6 & 6.8 & 7.3 & & 4.7 & 5.2 & 5.7 & & 5.8 & 5.8 & 4.1 & \\
\hline Worker & 14.1 & 17.4 & 13.0 & & 15.3 & 15.6 & 13.5 & & 15.2 & 12.6 & 16.6 & \\
\hline Self-employer & 11.0 & 22.1 & 20.2 & & 14.2 & 17.2 & 21.9 & & 16.8 & 17.4 & 19.2 & \\
\hline Student & 3.7 & 1.1 & 1.6 & & 2.1 & 3.1 & 1.0 & & 0.5 & 3.2 & 2.6 & \\
\hline Farmer & 53.4 & 39.5 & 29.5 & & 43.7 & 41.7 & 37.0 & & 50.8 & 42.6 & 29.0 & \\
\hline Retried & 4.7 & 2.6 & 3.1 & & 4.7 & 2.6 & 3.1 & & 1.6 & 4.2 & 4.7 & \\
\hline $\begin{array}{l}\text { Income, CNY/month/ } \\
\text { per-individual }\end{array}$ & $<0.001$ & & & & $<0.001$ & & & & 0.001 & & & \\
\hline$<1000$ & 31.9 & 21.6 & 11.4 & & 34.2 & 20.3 & 10.4 & & 26.2 & 19.5 & 19.2 & \\
\hline $1001-3000$ & 36.1 & 37.9 & 27.5 & & 27.4 & 39.1 & 34.9 & & 37.7 & 40.0 & 23.8 & \\
\hline$>3000$ & 31.9 & 40.5 & 61.1 & & 38.4 & 40.6 & 54.7 & & 36.1 & 40.5 & 57.0 & \\
\hline Smoking, yes & 38.7 & 36.8 & 59.1 & $<0.001$ & 36.3 & 43.8 & 54.7 & 0.001 & 41.9 & 41.1 & 51.8 & 0.062 \\
\hline Drinking, yes & 6.8 & 13.7 & 57.0 & $<0.001$ & 11.6 & 21.9 & 44.3 & $<0.001$ & 27.2 & 20.5 & 30.1 & 0.093 \\
\hline H. pylori infection, yes & 30.9 & 23.9 & 31.4 & 0.201 & 27.1 & 25.1 & 34.0 & 0.131 & 24.2 & 27.1 & 34.9 & 0.058 \\
\hline History of diabetes, yes & 6.8 & 7.4 & 2.6 & 0.083 & 7.9 & 6.3 & 2.6 & 0.07 & 5.2 & 4.7 & 6.7 & 0.674 \\
\hline $\begin{array}{l}\text { History of hypertension, } \\
\text { yes }\end{array}$ & 7.9 & 13.7 & 15.5 & 0.058 & 16.8 & 9.9 & 10.4 & 0.072 & 11.0 & 11.1 & 15.0 & 0.388 \\
\hline $\begin{array}{l}\text { History of taking } \\
\text { anticoagulants, yes }\end{array}$ & 3.7 & 4.2 & 8.3 & $\mid 0.09$ & 5.3 & 4.7 & 6.3 & 0.791 & 7.3 & 4.2 & 4.7 & 0.346 \\
\hline
\end{tabular}

Table 3. General characteristics of the study participants cross categories of dietary patterns scores.

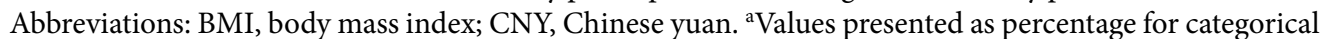
variables and mean \pm SD for continuous variables. ${ }^{b} \mathrm{Chi}$-square test for categorical variables and the ANOVA analyses for continuous variables.

production of reactive oxygen species, vasoconstriction, and increased vascular permeability ${ }^{38,39}$. A meta-analysis of cross-sectional studies found that moderate alcohol intake had a dose-response association with a reduction in $H$. pylori infection, but after adjusting for $H$. pylori infection status, alcohol drinking was significantly associated with gastritis in this study ${ }^{40}$.

There is little evidence of a direct relationship of fish consumption and chronic atrophic gastritis. A study by Tanigawa et al. ${ }^{41}$, reported that fish consumption promoted $H$. pylori-induced gastritis in a Mongolian gerbil model. More data are available on the effect of fish consumption on $H$. pylori infection. Tongtawee et al. ${ }^{42}$ reported that $H$. pylori infections were more frequent in those who ate pickled fish than in those who did not. Ikezaki et $a l .{ }^{43}$ reported that increased fish consumption was negatively associated with the success of oral treatment to eradication of $H$. pylori infection. The incorporation in cell membranes of highly unsaturated n-3 fatty acids from fish could increase the risk of $H$. pylori gastritis because of disruption of the clustering of lipid rafts and alteration of immune responses ${ }^{44,45}$. Yoshinori et al.$^{46}$ found that the serum concentration of docosahexaenoic acid, an n-3 polyunsaturated fatty acid, increased the risk of chronic atrophic gastritis $(\mathrm{OR}=2.2)$.

A high intake of legumes and cereal grains other than wheat and rice, has long been recognized as a poor man's dietary pattern ${ }^{47}$. Coarse cereals are recommended for their anti-inflammatory, anti-atherogenic, and antioxidant activities and for reducing the risk of type 2 diabetes, cardiovascular diseases, and cancer, but the effect 


\begin{tabular}{|l|l|l|l|l|l|l|l|}
\hline & $\begin{array}{l}\text { Cases/non- } \\
\text { cases }^{\mathbf{a}}\end{array}$ & Model 1 & $\begin{array}{l}\boldsymbol{p} \text { for } \\
\text { trend }\end{array}$ & Model 2 & $\begin{array}{l}\boldsymbol{p} \text { for } \\
\text { trend }\end{array}$ & Model 3 & $\begin{array}{l}\boldsymbol{p} \text { for } \\
\text { trend }\end{array}$ \\
\hline Alcohol and fish & & & 0.02 & & 0.041 & & 0.040 \\
\hline Tertile 1 (low) & $91 / 100$ & Reference & & Reference & & Reference & \\
\hline Tertile 2 & $87 / 103$ & $0.95(0.61-1.48)$ & & $0.98(0.62-1.56)$ & & $1.04(0.64-1.68)$ & \\
\hline Tertile 3 (high) & $108 / 85$ & $1.78(1.11-2.86)^{*}$ & & $1.83(1.07-3.13)^{*}$ & & $1.85(1.06-3.22)^{*}$ & \\
\hline Traditional & & & 0.404 & & 0.62 & & 0.969 \\
\hline Tertile 1 (low) & $98 / 92$ & Reference & & Reference & & Reference & \\
\hline Tertile 2 & $93 / 99$ & $1.09(0.69-1.70)$ & & $1.12(0.70-1.77)$ & & $1.16(0.72-1.87)$ & \\
\hline Tertile 3 (high) & $95 / 97$ & $1.23(0.76-1.99)$ & & $1.14(0.68-1.89)$ & & $1.00(0.59-1.70)$ & \\
\hline Coarse cereals & & & 0.004 & & 0.001 & & 0.005 \\
\hline Tertile 1 (low) & $87 / 104$ & Reference & & Reference & & Reference & \\
\hline Tertile 2 & $96 / 94$ & $1.44(0.93-2.25)$ & & $1.54(0.97-2.45)$ & & $1.55(0.96-2.50)$ & \\
\hline Tertile 3 (high) & $103 / 90$ & $1.95(1.24-3.07)^{*}$ & & $2.22(1.37-3.60)^{*}$ & & $2.05(1.24-3.39)^{*}$ & \\
\hline
\end{tabular}

Table 4. Multivariable-adjusted odds ratios for endoscopic gastric mucosal atrophy across tertiles of dietary patterns' scores. a Cases with gastric mucosal atrophy/non-cases in tertiles. Model 1: adjusted for age and gender. Model 2: further adjusted for year of education, residence, marital status, occupation, income, BMI (body mass index), smoking and drinking. Model 3: further adjusted for $H$. pylori infection, history of diabetes, history of hypertension, history of taking anticoagulants and total energy intake. ${ }^{*} p<0.05$.

of adherence to a "coarse cereals" diet on chronic gastritis has not been addressed ${ }^{47-49}$. The unfavorable effects of coarse cereals on chronic gastritis may be related to its relatively limited their nutritive value. For example some study participants routinely ate millet porridge for breakfast. The pericarp of millet is unpalatable and may contain antinutrients such as phytates and tannins ${ }^{47,50}$. Another possible explanation is that cereals other than yellow $\operatorname{corn}^{51}$, corn do not contain vitamin $\mathrm{B}_{12}$, vitamin $\mathrm{C}$, or vitamin $\mathrm{A}$, which could lead to gastritis-induced vitamin deficiency ${ }^{52}$ and gastric mucosal atrophy ${ }^{53}$. Tsigane et al. ${ }^{3}$ reported that frequent intake of soybean products was associated with an increased risk of atrophic gastritis.

This study has several strengths. First, to our knowledge, it is the first study to evaluate the association between dietary patterns and endoscopic gastric mucosal atrophy among adults in the city of Binzhou, Shandong Province, China. It provides evidence into the potential role of dietary modification in the prevention of gastric mucosal atrophy. Second, face-to-face interview ensured that the data we collected are accurate. Furthermore, we have adjusted for potential known confounders in our analyses. Nevertheless, several limitations also need to be considered. The analysis was controlled for many potential confounders, but family history of gastric cancer, physical activity, and mental health status were not considered and could have affected the results. Secondly, some participants may have had pre-existing gastric mucosal atrophy. Consequently, changing their usual dietary intake might have influenced our results. Thirdly, the cross-sectional design did not allow determining the causal relationship of dietary patterns and endoscopic gastric mucosal atrophy. Fourthly, recall bias and misclassification of study participants was not avoidable because the FGFQ had not been previously validated. Finally, because the subjects were recruited in Binzhou, China, the study findings might not be generalizable.

In conclusion, adherence to "alcohol and fish" or "coarse cereals" dietary patterns was associated with increased odds of endoscopic gastric mucosal atrophy. The results support confirmation in large prospective cohort studies.

Received: 18 March 2019; Accepted: 24 October 2019;

Published online: 12 November 2019

\section{References}

1. Weck, M. N. \& Brenner, H. Association of Helicobacter pylori infection with chronic atrophic gastritis: Meta-analyses according to type of disease definition. Int J Cancer 123, 874-881, https://doi.org/10.1002/ijc.23539 (2008).

2. Song, J. H. et al. High Salt Intake Is Associated with Atrophic Gastritis with Intestinal Metaplasia. Cancer Epidem Biomar 26, 1133-1138, https://doi.org/10.1158/1055-9965.Epi-16-1024 (2017).

3. Tsugane, S. et al. Helicobacter pylori, dietary factors, and atrophic gastritis in five Japanese populations with different gastric cancer mortality. Cancer Causes Control 4, 297-305 (1993).

4. Sipponen, P. \& Maaroos, H.-I. Chronic gastritis. Scand J Gastroenterol 50, 657-667, https://doi.org/10.3109/00365521.2015.101991 8 (2015).

5. Du, Y. et al. Chronic gastritis in China: a national multi-center survey. BMC Gastroenterol 14, 21, https://doi.org/10.1186/1471230x-14-21 (2014).

6. Kim, N. et al. Prevalence and Risk Factors of Atrophic Gastritis and Intestinal Metaplasia in a Korean Population Without Significant Gastroduodenal Disease. Helicobacter 13, 245-255, https://doi.org/10.1111/j.1523-5378.2008.00604.x (2008).

7. Yoon, H. \& Kim, N. Diagnosis and management of high risk group for gastric cancer. Gut Liver 9, 5-17, https://doi.org/10.5009/ gnl14118 (2015).

8. Song, H. Incidence of gastric cancer among patients with gastric precancerous lesions: observational cohort study in a low risk Western population (vol 351, h3867, 2015). Bmj 351, https://doi.org/10.1136/bmj.h4134 (2015).

9. Rugge, M., Fassan, M. \& Graham, D. Y. Epidemiology of Gastric Cancer. Gastric Cancer, 23-34, https://doi.org/10.1007/978-3-31915826-6_2 (2015)

10. Graham, D. Y. Helicobacter pylori update: gastric cancer, reliable therapy, and possible benefits. Gastroenterology 148, 719-731 e713, https://doi.org/10.1053/j.gastro.2015.01.040 (2015). 
11. D’Elia, L., Galletti, F. \& Strazzullo, P. Dietary salt intake and risk of gastric cancer. Cancer Treat Res 159, 83-95, https://doi. org/10.1007/978-3-642-38007-5_6 (2014).

12. Ge, S. et al. Association between Habitual Dietary Salt Intake and Risk of Gastric Cancer: A Systematic Review of Observational Studies. Gastroenterol Res Pract 2012, 808120, https://doi.org/10.1155/2012/808120 (2012).

13. Thapa, S., Fischbach, L. A., Delongchamp, R., Faramawi, M. F. \& Orloff, M. Association between Dietary Salt Intake and Progression in the Gastric Precancerous Process. Cancers 11, https://doi.org/10.3390/cancers11040467 (2019).

14. Yu, Y. et al. Risk factors for gastric intraepithelial neoplasia in Chinese adults: a case-control study. Cancer Manag Res 10, 2605-2613, https://doi.org/10.2147/cmar.s166472 (2018).

15. Kim, S. R. et al. Effect of Red, Processed, and White Meat Consumption on the Risk of Gastric Cancer: An Overall and Dose(-) Response Meta-Analysis. Nutrients 11, https://doi.org/10.3390/nu11040826 (2019).

16. Han, J. et al. Dietary Fat Intake and Risk of Gastric Cancer: A Meta-Analysis of Observational Studies. PLoS One 10, e0138580, https://doi.org/10.1371/journal.pone.0138580 (2015).

17. Bertuccio, P. et al. Dietary patterns and gastric cancer risk: a systematic review and meta-analysis. Ann Oncol 24, 1450-1458, https:// doi.org/10.1093/annonc/mdt108 (2013)

18. Bahmanyar, S. \& Ye, W. Dietary patterns and risk of squamous-cell carcinoma and adenocarcinoma of the esophagus and adenocarcinoma of the gastric cardia: a population-based case-control study in Sweden. Nutr Cancer 54, 171-178, https://doi. org/10.1207/s15327914nc5402_3 (2006).

19. Castello, A. et al. High adherence to the Western, Prudent, and Mediterranean dietary patterns and risk of gastric adenocarcinoma: MCC-Spain study. Gastric Cancer 21, 372-382, https://doi.org/10.1007/s10120-017-0774-x (2018).

20. Hu, F. B. Dietary pattern analysis: a new direction in nutritional epidemiology. Curr Opin Lipidol 13, 3-9, https://doi. org/10.1097/00041433-200202000-00002 (2002).

21. Shikany, J. M. et al. Southern dietary pattern is associated with hazard of acute coronary heart disease in the Reasons for Geographic and Racial Differences in Stroke (REGARDS) Study. Circulation 132, 804-814, https://doi.org/10.1161/ CIRCULATIONAHA.114.014421 (2015).

22. Mehta, R. S. et al. Association of dietary patterns with risk of colorectal cancer subtypes classified by Fusobacterium nucleatum in tumor tissue. JAMA. Oncol 3, 921-927, https://doi.org/10.1161/JAHA.117.008078 (2017).

23. Jessri, M. \& Rashidkhani, B. Dietary patterns and risk of gallbladder disease: a hospital-based case-control study in adult women. $J$ Health Popul Nutr 33, 39-49 (2015).

24. Lin, J. H. et al. Chinese expert consensus on the endoscopic management of foreign bodies in the upper gastrointestinal tract (2015, Shanghai, China). J Dig Dis 17, 65-78, https://doi.org/10.1111/1751-2980.12318 (2016).

25. Uotani, T. \& Graham, D. Y. Diagnosis of Helicobacter pylori using the rapid urease test. Ann Transl Med 3, 1-7, https://doi. org/10.3978/j.issn.2305-5839.2014.12.04 (2015).

26. Schafer, J. L. \& Graham, J. W. Missing data: our view of the state of the art. Psycho Methods 7, 147-177, https://doi.org/10.1037/1082989x.7.2.147 (2002)

27. Sterne, J. A. et al. Multiple imputation for missing data in epidemiological and clinical research: potential and pitfalls. Bmj 339, 157-159, https://doi.org/10.1136/bmj.b2393 (2009).

28. Rubin, D. B. Multiple imputation after 18+ years. J Am stat Assoc 91, 473-489, https://doi.org/10.1080/01621459.1996.10476908 (1996).

29. Nordenstedt, H. et al. Helicobacter pylori-negative gastritis: prevalence and risk factors. Am J Gastroenterol 108, 65-71, https://doi. org/10.1038/ajg.2012.372 (2013).

30. Shu, L. et al. Dietary patterns and stomach cancer: a meta-analysis. Nutr Cancer 65, 1105-1115, https://doi.org/10.1080/01635581. 2013.828086 (2013).

31. Schwingshackl, L., Schwedhelm, C., Galbete, C. \& Hoffmann, G. Adherence to Mediterranean Diet and Risk of Cancer: An Updated Systematic Review and Meta-Analysis. Nutrients 9, https://doi.org/10.3390/nu9101063 (2017).

32. You, W. C. et al. Helicobacter pylori infection, garlic intake and precancerous lesions in a Chinese population at low risk of gastric cancer. Int J Epidemiol 27, 941-944, https://doi.org/10.1093/ije/27.6.941 (1998).

33. Gao, L., Weck, M. N., Stegmaier, C., Rothenbacher, D. \& Brenner, H. Alcohol consumption and chronic atrophic gastritis: population-based study among 9,444 older adults from Germany. Int J Cancer 125, 2918-2922, https://doi.org/10.1002/ijc.24618 (2009).

34. Ozasa, K. et al. Helicobacter pylori infection and atrophic gastritis: a nested case-control study in a rural town in Japan. Dig Dis Sci 44, 253-256, https://doi.org/10.1023/a:1026633913154 (1999).

35. Namekata, T. et al. Chronic atrophic gastritis and Helicobacter pylori infection among Japanese Americans in Seattle. Am J Epidemiol 151, 820-830, https://doi.org/10.1093/oxfordjournals.aje.a010282 (2000).

36. Endo, K. et al. Risk factors for atrophic gastritis in the Japanese young and middle-aged: a study using double-contrast upper gastrointestinal barium X-ray radiography. Jpn J Radiol, https://doi.org/10.1007/s11604-018-0782-8 (2018).

37. Song, J. H., Kim, S. G., Jin, E. H., Lim, J. H. \& Yang, S. Y. Risk Factors for Gastric Tumorigenesis in Underlying Gastric Mucosal Atrophy. Gut Liver 11, 612-619, https://doi.org/10.5009/gnl16488 (2017).

38. Teyssen, S. \& Singer, M. V. Alcohol-related diseases of the oesophagus and stomach. Best Pract Res Clin Gastroenterol 17, 557-573 (2003).

39. Bode, C. \& Bode, J. C. Alcohol's role in gastrointestinal tract disorders. Alcohol Health Res World 21, 76-83 (1997).

40. Liu, S. Y. et al. Alcohol intake and Helicobacter pylori infection: a dose-response meta-analysis of observational studies. Infect Dis (Lond) 48, 303-309, https://doi.org/10.3109/23744235.2015.1113556 (2016).

41. Tanigawa, T. et al. Marked enhancement by fish meal of Helicobacter pylori-induced gastritis in Mongolian gerbils. Jpn J Cancer Res 91, 769-773, https://doi.org/10.1111/j.1349-7006.2000.tb01011.x (2000).

42. Tongtawee, T. et al. Characteristics and Risk Factors of Helicobacter pylori Associated Gastritis: A Prospective Cross-Sectional Study in Northeast Thailand. Gastroenterol Res Pract 2016, 9130602, https://doi.org/10.1155/2016/9130602 (2016).

43. Ikezaki, H. et al. Higher dietary cholesterol and omega-3 fatty acid intakes are associated with a lower success rate of Helicobacter pylori eradication therapy in Japan. Am J Clin Nutr 106, 581-588, https://doi.org/10.3945/ajcn.116.144873 (2017).

44. Yaqoob, P. \& Shaikh, S. R. The nutritional and clinical significance of lipid rafts. Curr Opin Clin Nutr Metab Care 13, 156-166, https://doi.org/10.1097/MCO.0b013e328335725b (2010).

45. Fenton, J. I., Hord, N. G., Ghosh, S. \& Gurzell, E. A. Immunomodulation by dietary long chain omega-3 fatty acids and the potential for adverse health outcomes. Prostaglandins Leukot Essent Fatty Acids 89, 379-390, https://doi.org/10.1016/j.plefa.2013.09.011 (2013).

46. Ito, Y., Suzuki, K., Imai, H., Sakamoto, H. \& Nakano, H. Effects of polyunsaturated fatty acids on atrophic gastritis in a Japanese population. Cancer Lett 163, 171-178, https://doi.org/10.1016/s0304-3835(00)00686-8 (2001).

47. Kaur, K. D., Jha, A., Sabikhi, L. \& Singh, A. K. Significance of coarse cereals in health and nutrition: a review. J Food Sci Technol 51, 1429-1441, https://doi.org/10.1007/s13197-011-0612-9 (2014).

48. Bhupathiraju, S. N. et al. Glycemic index, glycemic load, and risk of type 2 diabetes: results from 3 large US cohorts and an updated meta-analysis. Am J Clin Nutr 100, 218-232, https://doi.org/10.3945/ajcn.113.079533 (2014).

49. Ding, Z. et al. [Effect of compound coarse grain food on insulin resistance and expression of PPARgamma in rat]. Wei Sheng Yan Jiu 39, 29-31, 35 (2010). 
50. Devisetti, R., Yadahally, S. N. \& Bhattacharya, S. Nutrients and antinutrients in foxtail and proso millet milled fractions: Evaluation of their flour functionality. Lwt-Food Sci Technol 59, 889-895, https://doi.org/10.1016/j.lwt.2014.07.003 (2014).

51. Cordain, L. Cereal grains: humanity's double-edged sword. World Rev Nutr Diet 84, 19-73 (1999).

52. Cavalcoli, F., Zilli, A., Conte, D. \& Massironi, S. Micronutrient deficiencies in patients with chronic atrophic autoimmune gastritis: A review. World J Gastroenterol 23, 563-572, https://doi.org/10.3748/wjg.v23.i4.563 (2017).

53. Miranti, E. H. et al. Low vitamin B12 increases risk of gastric cancer: A prospective study of one-carbon metabolism nutrients and risk of upper gastrointestinal tract cancer. Int J Cancer 141, 1120-1129, https://doi.org/10.1002/ijc.30809 (2017).

\section{Acknowledgements}

We thank the study participants and the clinical staff for their great assistant with this study. Supported by Shandong provincial medicine and health science and technology development plan (Grant No. 2017WS549). The sponsors had no role in the study design, data collection and analysis, as well as writing of the manuscript.

\section{Author contributions}

A.G.M., S.L. and T.G. were involved in the study design, drafting the protocol and manuscript. S.L. was involved in questionnaire survey. S.L., T.G., C.X.S. and M.R.J. were involved in data analysis. C.X.L., T.G. and X.B.M. were involved in performing endoscopy. All authors contributed to the final submitted version and agree to be responsible for all the work.

\section{Competing interests}

The authors declare no competing interests.

\section{Additional information}

Supplementary information is available for this paper at https://doi.org/10.1038/s41598-019-52951-7.

Correspondence and requests for materials should be addressed to A.M.

Reprints and permissions information is available at www.nature.com/reprints.

Publisher's note Springer Nature remains neutral with regard to jurisdictional claims in published maps and institutional affiliations.

Open Access This article is licensed under a Creative Commons Attribution 4.0 International License, which permits use, sharing, adaptation, distribution and reproduction in any medium or format, as long as you give appropriate credit to the original author(s) and the source, provide a link to the Creative Commons license, and indicate if changes were made. The images or other third party material in this article are included in the article's Creative Commons license, unless indicated otherwise in a credit line to the material. If material is not included in the article's Creative Commons license and your intended use is not permitted by statutory regulation or exceeds the permitted use, you will need to obtain permission directly from the copyright holder. To view a copy of this license, visit http://creativecommons.org/licenses/by/4.0/.

(c) The Author(s) 2019 